\title{
O santo e a cura: performances e subjetividades no mausoléu de Sidi ‘Ali ben Hamdouche, Marrocos
}

The saint and the cure: performance and subjectivity in the Sidi mausoleum 'Ali ben Hamdouche, in Marrocos

\section{Bruno Ferraz Bartel}

Brasil. Universidade Federal Fluminense. Doutor em Antropologia pelo Programa de Pós-Graduação em Antropologia pela Universidade Federal Fluminense (PPGA/UFF). Integrante do Instituto de Estudos Comparados em Administração Institucional de Conflitos (INCT-InEAC) e do Núcleo de Estudos do Oriente Médio (Neom), localizados na Universidade Federal Fluminense (UFF). ID ORCID: https://orcid.org/0000-0003-4788-0204.E-mail: brunodzk@yahoo.com.br

\section{Resumo}

$\mathrm{O}$ artigo analisa os princípios operativos nas práticas de cura dos fuqaha (especialistas religiosos islâmicos) atuantes no mausoléu de Sidi 'Ali ben Hamdouche, localizado na região Fez-Meknes, Marrocos. Os argumentos demonstram que, para além dos símbolos e das ações rituais de cura atuantes em parceria com as dimensões sensoriais, emotivas e cognitivas dos peregrinos, os usos dos objetos (materialidade) e as concepções femininas (gênero) presentes nesses rituais permitem apontar as disputas sobre o que se concebe como uma "tradição" disponível, uma vez que diferentes níveis de mobilização são exercidos pelos especialistas religiosos por meio de suas formas perceptivas de eficácia e devoção junto aos indivíduos. Isso só é possível uma vez que existe toda uma multiplicidade de opiniões, sentimentos e práticas mobilizadas voltadas não apenas para a vivência de uma ortodoxia envolvendo o culto aos santos no Marrocos, mas que, sobretudo, lida com questões de ambuiguidades e/ou (im) perfeições morais dos sujeitos.

Palavras-chave: Islã, Marrocos, Ritual, Performance, Subjetividade. 


\section{Abstract}

This article analyzes the operational principles in the healing practices of the fuqaha (Islamic religion specialists) at the Sidi "Ali ben Hamdouche" mausoleum, situated in the Fez-Meknes region of Morocco. The arguments presented here show that-beyond the symbols and ritual actions of healing paired with the pilgrims' sensory, emotional and cognitive dimensions-, the use of objects (material) and feminine conceptions (gender) indicate disputes over what is understood as an available "tradition", given the different levels of mobilization developed by religious specialists using their perceptive forms of efficacy and devotion. This is possible since there is a multiplicity of opinions, feelings and practices mobilized not only by orthodoxy concerning the cult of saints in Morocco, but also by the presence of ambiguity or moral (im)perfection in the subjects.

Keywords: Islam, Morocco, Ritual, Performance, Subjectivity.

A noção de sistema terapêutico no Marrocos $^{1}$ parte da premissa de que os indivíduos podem apresentar, em algum momento de suas vidas, desequilíbrios físicos ou psicológicos em decorrência da ação de gênios ${ }^{2}$ (jnun, sing. jinn). Diante de tais ocorrências, o recurso a alguma prática religiosa se faz presente como forma de promover a resolução definitiva ou, como em alguns casos, apenas a minimização de seus efeitos. A eficácia desses ritos contém um conjunto de desejos e de motivações para os que buscam a cura e traduz uma série de dispositivos de controle ${ }^{3}$ existentes que exprimem a manifestação e a experiência com o que se denomina de "sagrado".

\footnotetext{
Existe uma pluralidade de sistemas terapêuticos no país que incluem elementos naturais, medicina profética com base no Alcorão ou até mesmo teoria humoral, de maneira que muitas aflições experienciadas pelos indivíduos são tratadas por meio desses sistemas e de modo justapostos (AMSTER; EL AOUED, 2013; AOUATTAH, 2008). Para a relação entre os conteúdos e as atribuições simbólicas dos sistemas médicos com a ciência antropológica, ver Good (1994).

2 O termo se refere aos seres invisíveis que compõem o universo simbólico da religião islâmica. Os gênios são seres criados por Allah a partir do fogo. A palavra jinn também é usada nos demais países que têm o islã como código e discurso cultural.

3 A temática de gênero é central neste debate, uma vez que os dados empíricos tratam da relação entre peregrinas (mulheres) e especialistas terapêuticos (homens). Dessa forma, as etnografias abordam o reconhecimento, por parte das peregrinas, da existência de homens capazes de mobilizar a bênção divina (baraka) dos santos devido às suas filiações genealógicas com esses agentes religiosos (RHANI,
} 
O contexto marroquino registra uma complexidade de atitudes e práticas religiosas com as quais indivíduos estabelecem união com as forças sagradas a fim de minimizar suas adversidades ${ }^{4}$ na vida cotidiana ${ }^{5}$. A noção de sistema terapêutico afirma a existência de uma relação com as figuras sagradas que, por meio de determinados símbolos manipulados, garantem a resolução dos infortúnios vividos (AOUATTAH, 2008; CRAPANZANO, 1973). Essas forças disponíveis refletem as formas com as quais os indivíduos construirão as interpretações sobre os males identificados e, principalmente, sobre as ações dos agentes responsáveis pela experiência com o "sagrado".

Este artigo analisa os princípios operativos nas práticas de cura dos especialistas religiosos islâmicos (fuqaha, sing. $\left.f q i h^{6}\right)$ atuantes no mausoléu de Sidi 'Ali ben Hamdouche, um importante santo (wali, pl. awliya) da região marroquina Fez-Meknes. Meus argumentos demonstram que os símbolos mobilizados e as ações rituais desses agentes religiosos atuam em parceria com

2008). Cabe ressaltar que a atuação de agentes femininos, como as videntes (shuwwafat), por exemplo, é muito difundida no contexto marroquino (RAUSCH, 2000). Nesse caso, elas são as responsáveis por tensionar os discursos que visam estabelecer a existência de uma dicotomia entre uma ortodoxia islâmica em oposição a uma devoção popular no país.

4 A busca por emprego, a materialização do casamento, a geração de filhos ou a cura de doenças fazem parte do conjunto de temáticas demandadas, majoritariamente por mulheres, no cotidiano da vida religiosa em Sidi 'Ali (BARTEL, 2016b).

5 O culto aos santos no Magreb central (Marrocos, Argélia e Tunísia) é notório e de longa data na região (DERMENGHEM, 1954). Ele tem sido o responsável, de modo geral, pela produção de relíquias e territórios sagrados por delimitar noções de santidade/autoridade e, por conseguinte, sustentar a estrutura da ordem social vigente por meio da interação desses elementos (WHEELER, 2006). No Marrocos, os locais (túmulos) e territórios sagrados (mausoléus) vinculados aos santos são fundamentais para explicitar as relações que imbricam tanto o poder político quanto o religioso devido ao papel que os diversos circuitos de peregrinação adquirem no país (CRAPANZANO, 1973). As capacidades miraculosas dos santos marcam uma posição de proeminência no contexto marroquino a partir de seus mais diversos usos entre os peregrinos que, por meio de suas interpretações, acabam por multiplicar os significados das hagiografias dessas personalidades (DERMENGHEM, 1954). No entanto, os significados culturais presentes nos santuários marroquinos passaram por distintas modificações no decorrer dos séculos (EICKELMAN, 1976).

6 O fqih é um estudioso e conhecedor do Alcorão (objeto textual da recitação da palavra divina pelo profeta Mohammed entre os anos de 610 e 632 a.D.). O termo $f q i h$ pode assumir três funções distintas. Em primeiro lugar, ele é reconhecido como jurista. Em segundo, é tido como uma pessoa capaz de recitar o Alcorão devido ao grau de memorização dos conteúdos. Por último, pode remeter à figura de professor. No Marrocos, essa pluridimensionalidade do fqih está mais associada à ideia de uma ortodoxia islâmica por meio de um domínio do texto escrito ou recitado (EICKELMAN, 1985). A participação de mulheres nessas posições de autoridade é recente (durante o atual governo de Mohammed VI), concentrando-se apenas em algumas mesquitas do país (núcleos urbanos) como professoras, ou seja, como alguém disposto a fornecer respostas para o entendimento de alguma questão ligada à religião islâmica. No meu contexto, as habilidades de recitar o Alcorão resumiam a representação dos homens como fuqaha atuantes no mausoléu de Sidi ‘Ali. 
as dimensões sensoriais, emotivas e cognitivas dos indivíduos (especialmente entre mulheres) que, durante a peregrinação $\left(\right.$ ziyara $\left.^{7}\right)$, almejam uma experiência terapêutica. Ressalto que o caráter sistêmico das experiências terapêuticas deve ser analisado tanto por parte de "quem cura", quanto por "quem a almeja”, e não apenas na indicação de quais elementos estariam relacionados à reorganização da vida social dos indivíduos ${ }^{8}$. Além disso, os usos dos objetos (materialidade) e as concepções femininas (gênero) presentes nesses rituais permitem apontar as disputas sobre o que se concebe como uma "tradição" disponível, uma vez que diferentes níveis de mobilização são exercidos pelos especialistas religiosos por meio de suas formas perceptivas de eficácia e devoção com os indivíduos. Isso só é possível uma vez que existe toda uma multiplicidade de opiniões, sentimentos e práticas mobilizadas voltadas não apenas à vivência de uma tradição ${ }^{9}$ (ortodoxia) envolvendo o culto aos santos no Marrocos, mas que, sobretudo, lida com questões de ambuiguidades ${ }^{10}$ e/ou (im)perfeições morais ${ }^{11}$ dos sujeitos.

Cabe salientar que o tema da ortodoxia ganha contorno no Marrocos justamente por seus usos destinados às questões morais envolvendo a relação entre materialidade (objetos) e, principalmente, gênero (mulheres). O simbolismo contido na ideia de purificação corporal durante a peregrinação inscreve as formas, usos e trajetórias (APPADURAI, 2008) desses objetos em consonância com as práticas

7 O termo equivale à experiência da peregrinação relacionada a um local sagrado, ou seja, a um santuário.

${ }^{8}$ No Marrocos, o termo santidade procura expressar as noções de proteção ou de intercessão na vida dos indivíduos (wilaya) e a de alguém próximo de Deus (walaya). Diante desse contexto, pode-se concluir que essa força ou potência religiosa equivaleria a uma bênção e que poderia ter efeito miraculoso na vida de quem entra em contato com a pessoa ou coisa que a possui (CORNELL, 1998). No Brasil, os santos podem ser vistos como atores essenciais dentro de uma rede de relações que unem mitos, devotos, lugares ou objetos.

9 Talal Asad (1986, p. 14) define tradição como "discursos que visam instruir os praticantes a respeito do propósito e da forma correta de uma determinada prática que, precisamente porque foi estabelecida, tem uma história. Esses discursos se relacionam conceitualmente com um passado (quando a prática foi estabelecida e a partir da qual o conhecimento sobre o seu propósito e performance correta foi transmitido) e um futuro (como o propósito daquela prática pode ser mais bem assegurado no curto e no longo prazo ou porque ela deveria ser modificada ou abandonada) através de um presente (como ela é ligada a outras práticas, instituições e condições sociais)".

${ }^{10}$ A moralidade não é um sistema coerente, mas um conglomerado incoerente e não sistemático de diferentes registros morais que existem paralelamente e frequentemente se contradizem (SCHIELKE, 2009).

${ }_{11}$ A (im)perfeição moral, por exemplo, é crucial para o mundo religioso, uma vez que permite colocar estruturas e ideias da vida social em termos das trajetórias de vida dos sujeitos (BANDAK; BOYLSTON, 2014). 
de cura voltadas para esse público no país ${ }^{12}$. A temática de gênero e sua relação com os santos no Marrocos registra uma série de problemáticas (LAGHZAOUI, 1992) desenvolvidas a partir de múltiplas formas religiosas construídas após a independência do país (DWYER, 1978; EL HAITAMI, 2013). Essas pesquisas versaram sobre a importância das expressões religiosas constituídas pelas mulheres para se contrapor à ideia clássica de uma suposta "ortodoxia masculina" islâmica (GELLNER, 1968). Esses trabalhos se debruçaram sobre o estudo da prática e do significado da religião islâmica experienciado no dia a dia, que inevitavelmente combinava os elementos "ortodoxos" e "populares", ao invés de negligenciá-los como algo simples e sem interesse teórico (EICKELMAN, 1976).

As experiências de cura, por meio do acionamento dos santos entre as mulheres marroquinas, não se restringem às meras sociabilidades e práticas catárticas (MERNISSI, 1981) que elas podem adquirir. Alguns trabalhos trataram a questão da busca por esses agentes religiosos em situações concretas de aflição. Muitos demonstraram que nem sempre as escolhas feitas pelas mulheres incidiam sobre o mesmo santo. De fato se tem dado a ênfase de que as mulheres recorrem a múltiplos santos por meio de suas "especialidades" reconhecidas socialmente (LAGHZAOUI, 1992). Nesse sentido, a circulação entre os vários mausoléus na tentativa de alcançar a referida "eficácia" mantém um horizonte de conectividade com as práticas religiosas das mulheres, do ponto de vista dos significados de quem almeja passar por essas experiências.

O mausoléu de Sidi 'Ali ben Hamdouche atrai muitas pessoas durante o período de celebrações do nascimento do Profeta (mawlid al-nabawi - denominado moussem no Marrocos), não somente das províncias de Fez-Meknes, mas também do restante do país. Diversos peregrinos, especialmente mulheres, realizam seus deslocamentos anuais (ziyara) com o objetivo de desenvolverem práticas terapêuticas com o santo local, reforçando, assim, a condição desse fenômeno consonante com os demais sítios devocionais do Marrocos contemporâneo (NAAMOUNI, 1993). De fato, a figura dos santos ainda se

\footnotetext{
${ }_{12}$ A possessão tem sido um dos principais temas envolvendo a prática de cura entre mulheres (CRAPANZANO, 1973; RAUSCH, 2000). A participação masculina existe, mas sempre foi considerada de baixa expressividade e com análises pouco elucidativas sobre a questão de gênero (BARTEL, 2016b; WESTERMARCK, 1968).
} 
destaca no país por meio do sistema de curas construídas historicamente (AMSTER; EL AOUED, 2013; DERMENGHEM, 1954; WESTERMARCK, 1968), por mais que determinadas controvérsias façam parte de sua composição de tempos em tempos, como tem sido o caso da vila de Sidi 'Ali' ${ }^{13}$.

Além disso, cabe destacar o papel político desses sítios devocionais para a monarquia marroquina. Se os santos já desempenharam um papel importante de questionamento de autoridades locais (CORNELL, 1998), hoje seus territórios sagrados (mausoléus) fazem parte de um conjunto de preocupações de setores governamentais, como o Ministério de Habous e Assuntos Islâmicos $\left(\mathrm{MHAI}^{14}\right)$.

Essa pesquisa fez parte de um período de dez meses de trabalho de campo, entre janeiro e novembro de 2012, na vila de Sidi 'Ali - comuna de Merhasiyne (BARTEL, 2016b). Além disso, realizei visitas periódicas, em janeiro de 2015, a fim de evidenciar algumas mudanças quanto ao uso interno do mausoléu por parte de seus responsáveis ${ }^{15}$ (BARTEL, 2016a). Nesta etnografia, privilegio as ações dos especialistas religiosos (fuqaha), descendentes de Sidi 'Ali ben Hamdouche ${ }^{16}$ (1666-1722), em suas interações com os peregrinos. O método

${ }^{13}$ Outras práticas devocionais classificadas como "heterodoxas", como as flagelações rituais sufis e a presença de videntes (shuwwafat) em Sidi 'Ali durante o moussem, criam até hoje uma imagem pública da vila como um local permeado de inovações (bid'a) para com a religião islâmica. Nos últimos anos, a imagem pública do moussem na vila de Sidi 'Ali tem sido alvo de intensos debates entre descendentes, discípulos e devotos do santo, o que contribui para complexificar algumas questões do campo político-religioso local.

14 Usarei essa sigla para me referir a essa instituição no texto. O Ministério de Habous (termo islâmico relacionado à legislação de propriedade da terra) e de Assuntos Islâmicos foi criado pela monarquia marroquina em 1955 como uma maneira de dispor de um instrumento burocrático sobre a religião islâmica no país. O governo visa controlar a partir dele as práticas religiosas públicas por meio de um sistema oficial que fixa normas, condutas e seus limites. Uma vez que a monarquia marroquina constitui o próprio campo político por onde os demais agentes sociais orbitam, pode-se dizer que o Estado faz parte da estrutura de autoridade do que se denomina de "tradição" no país. Sobre os usos terapêuticos contidos nos cultos aos santos, existe todo um debate de legitimação dessas práticas junto ao campo da medicina, por exemplo (AMSTER; EL AOUED, 2013; AOUATTAH, 2008), do qual as instituições governamentais não se omitem.

15 A ideia de criar uma associação (rabita), em 2006, para defender os interesses dos descendentes de Sidi 'Ali, estabeleceu um novo arranjo organizacional local. O controle do mausoléu do santo compreendeu não somente a organização de suas áreas físicas para receber os peregrinos, mas também se realizou a partir da divisão do montante arrecadado gerado pelas visitações ao longo do ano. Dinheiro em espécie e determinados objetos (pacote de velas, incensos, tapetes, pães e até animais, como cabras e ovelhas) eram constantemente doados pelos peregrinos aos responsáveis locais. No final de cada evento relacionado ao calendário islâmico, a associação organizava uma reunião entre seus membros, dos mais variados centros religiosos do país, para dividir a quantia acumulada durante esses períodos.

${ }^{16}$ A figura de Sidi 'Ali, segundo os descendentes locais, está relacionada à descendência de Idriss I (745-791), responsável por trazer o islã ao Marrocos e por ter fundado a primeira dinastia (Idríssidas) sobre os territórios que constituiriam o país. 
que fundamentou minhas interpretações foi o da observação direta, que consiste no envolvimento do pesquisador nas atividades do grupo social no qual está inserido, a fim de estabelecer os princípios conceituais e as ações rituais que organizam as experiências de seus membros ${ }^{17}$.

Em termos práticos, isso significa que eu visitava, com a devida autorização, o mausoléu do santo junto com os peregrinos e acompanhava as demais atividades realizadas por eles (compra de artigos religiosos nas lojas disponíveis, por exemplo) durante a construção do ritual de peregrinação na vila. Eu também frequentava a casa de alguns dos descendentes (shurafa, sing. sharif) de Sidi 'Ali para ter acesso às representações acerca de como eles analisavam a importância do mausoléu na dinâmica da vila. Além disso, muitas das conversas que pude presenciar entre os descendentes do santo explicitavam algumas das práticas recorrentes na preservação da estrutura religiosa local.

Usarei três referências como suporte ao meu campo etnográfico, a partir de exemplos extraídos de distintas sociedades islâmicas (Marrocos, Tunísia e Síria). As duas primeiras interpretam o processo de cura por intermédio de santos e/ou gênios (BOISSEVAIN, 2006; CRAPANZANO, 1973), tendo no contexto tunisiano um contraponto para refletir o papel das mulheres como especialistas do sistema terapêutico (BOISSEVAIN, 2006). Quanto à última, ela fornece uma contribuição específica quanto ao papel das experiências dos indivíduos na produção de rituais (PINTO, 2002).

A etnografia de Vincent Crapanzano (1973), no final da década de 1960 entre os membros da confraria ${ }^{18}$ Hamadsha no Marrocos, demonstrou que a noção de um sistema terapêutico operante consiste em promover uma série de procedimentos capazes de mover um "estado de doença" em direção a um "estado

\footnotetext{
${ }_{17}$ Durante o trabalho de campo, realizei a maioria das entrevistas com os seis descendentes do santo local, sendo dois deles fuqaha. Além deles, também entrevistei mais cinco descendentes que se ocupavam dos espaços internos do mausoléu. No entanto, estes não foram privilegiados no texto porque não exerciam qualquer proeminência no campo religioso local, pois apenas realizavam a coleta das ofertas dos peregrinos. As entrevistas foram conduzidas em francês, devido à minha falta de domínio do árabe coloquial marroquino (darija). Desta língua, eu domino apenas o vocabulário religioso e algum conhecimento dialetal para a realização de conversas informais.

18 Organizações ou irmandades religiosas que têm como característica a filiação (sistema de linhagens) a um santo e a presença de ritmos musicais na execução de ritos particulares.
} 
de cura". Santos (awliya), gênios (jnun) e bênção divina (baraka $a^{19}$ ) são considerados signos dos estados físicos e símbolos dos processos socioculturais manipulados por seus especialistas (moqaddemine $e^{20}$, sing. moqaddim) como forma de reduzir as ansiedades ou de eliminação dos sintomas pelos pacientes. O autor destacou o sistema terapêutico atuante nas peregrinações da Hamadsha, ora a partir da presença dos santos da confraria (Sidi 'Ali ben Hamdouche e seu discípulo Sidi Ahmed Dghoughi), ora através da evocação de Aisha Qandisha ${ }^{21}$, e indicou a relevância dos rituais identitários do grupo (hadrat ${ }^{22}$, sing. hadra), tanto na eliminação dos males identificados quanto na preservação dos estados de saúde anteriores.

A ideia recorrente de que os jnun precisam se "satisfazer" dos corpos dos pacientes coloca os rituais de possessão como um ponto central na teoria terapêutica da Hamadsha, segundo Crapanzano (1973, p. 219). Essa teoria estabelece uma tensão entre homens e mulheres referente aos processos de cura, ao criar os discursos de inferioridade, natureza traiçoeira e de insatisfação sexual sobre as mulheres, sobretudo pela justificativa de que elas seriam "mais suscetíveis" aos ataques dos jnun.

O modelo de cura do autor se baseia na força das crenças coletivas influentes sobre os indivíduos e na dicotomia signo-símbolo, na qual os mitos dos santos desempenham papel fundamental na promoção de uma "eficácia simbólica" no sentido lévi-straussiano do termo. Entretanto a ideia de colapso (função de catarse) na terapia da Hamadsha é passível de críticas. Determinados indivíduos exibem algumas dessas funções antes, durante e até mesmo depois das intervenções dos especialistas religiosos (moqaddemine), atestando, assim, o caráter subjetivo contido na maioria dessas experiências.

\footnotetext{
19 A noção de baraka é usualmente representada na religião islâmica como uma força (bênção) capaz de provocar prosperidade material, bem-estar físico, satisfação corporal, plenitude ou sorte.

${ }^{20}$ O termo se refere ao líder de um grupo religioso que tem como base as experiências desenvolvidas por um santo.

${ }^{21}$ Aisha Qandisha é um jinn feminino (jinniya) presente no imaginário popular do Marrocos (BARTEL, 2016b).

${ }^{22}$ No Marrocos, o termo hadra acaba tendo vários usos: pode se constituir tanto pelas sessões de possessão envolvendo jnun, realizadas entre as confrarias religiosas, quanto pelos ritos de êxtase que evocam a figura de um santo (wali) ou até mesmo podem expressar os momentos rituais das ordens sufis, que são centradas na figura de um mestre (shaykh).
} 
Além disso, o excesso de termos extraídos da psicanálise não contribui, de maneira satisfatória, para a interpretação dos diagnósticos (o sujeito não constrói um mito individual como pressupõe o modelo lévi-straussiano) e das ações que visam combater os males dos indivíduos, uma vez que a transformação simbólica tem certos limites.

A etnografia de Kátia Boissevain (2006) sobre as representações de Sayyda Mannubiya, na Tunísia, demonstra os mecanismos que perpetuam o culto à santa, principalmente entre as mulheres, por meio de dois santuários existentes no país. O sistema terapêutico atuante nesses locais é realizado por mulheres específicas (ukila), que fornecem as substâncias responsáveis pela baraka aos peregrinos quando estes ofertam algum dinheiro, depois de receberem a recitação da Surat al-Fatiha ${ }^{23}$ sobre o túmulo (qbar, pl. qbour) da santa. Quando se trata do contato com os espíritos (jnun) que manifestam doenças, as possessões rituais não podem ocorrer até que pelo menos um diagnóstico possa ser feito por intermédio dessas especialistas religiosas.

A indicação desse tipo de culto feminino permite reformular as hipóteses quanto às funções ocasionalmente complementares ou ambivalentes de algumas práticas religiosas, em especial aquelas referentes aos ritos de possessão. As distintas origens sociais dos peregrinos contemporâneos permitem repensar as modalidades de apropriação do culto à Sayyda Mannubiya, tomando por base sua suposta homogeneidade e evolução ao longo do tempo. O uso de um vocabulário de parentesco uniforme e a divisão sexual existente que promovem as mudanças religiosas colocam a questão da articulação entre a função do culto e sua gestão comunitária, em que cada um desses modos de funcionalidade apresenta suas legitimidades sob a forma de diferentes registros.

As mulheres estabelecem um sistema que incide na organização dos processos terapêuticos por meio da intercessão da figura de Sayyda Mannubiya. Além disso, elas preparam os rituais específicos (hadrat) para celebrar a figura da santa como uma mulher exemplar e de poder, capaz de responder aos desafios impostos pelas doenças e as agências dos jnun em seus corpos.

\footnotetext{
${ }^{23}$ Primeiro capítulo do Alcorão.
} 
Uma das conclusões da autora é a de que não ocorre qualquer homogeneidade social no culto aos santos, o que permite pensar o papel das variações nesses tipos de experiências religiosas. A tese de que a possessão adquire um caráter multifuncional, em decorrência das diversas expectativas de cura, especialmente entre as mulheres, permite que os adeptos dos distintos santos (Sayyda Mannubiya e Sidi Bel Hasen al-Shadhili) possam se reunir a partir de uma ideia de "proteção". Além disso, as modalidades de acesso são o segundo ponto de contraste entre as duas formas de relação com o "sagrado". No primeiro caso, ele se realiza a partir de um ato voluntário: o indivíduo, de fato, escolhe entrar na tariq $a^{24}$ Shadhiliya. No segundo caso acontece uma filiação por intermédio da possessão. Assim, os santos locais decidem sobre o futuro de seus devotos.

Boissevain (2006) e Crapanzano (1973) ainda relegam o papel e a posição das experiências do ponto de vista dos indivíduos tidos como "doentes". De fato, o que os especialistas religiosos de cura e/ou de proteção (moqaddemine e ukila) têm encontrado é um campo de subjetividades existentes. A tese de Paulo Gabriel Hilu da Rocha Pinto (2002) focalizou a corporificação (embodiment) dos elementos doutrinais e práticos da tradição sufi, presentes entre alguns grupos no norte da Síria, como uma dimensão da subjetividade existencial definida também por meio da noção de self5. Se a relação entre selfe experiência pode contribuir para a análise concreta dos princípios operacionais atuantes em um sistema religioso, como sugere a proposta do autor, esse tipo de abordagem pode ser útil no exame das situações que envolvem - como no meu caso o que denomino de processo terapêutico entre os fuqaha do mausoléu de Sidi 'Ali ben Hamdouche.

A etnografia de Pinto (2002), baseado no trabalho de Thomas Csordas (1994), apresenta a intrínseca relação entre self e experiência, na qual se destaca que alguns aspectos dos fenômenos culturais, como o campo do simbolismo, não poderiam ser propriamente entendidos por meio

\footnotetext{
${ }^{24}$ Caminhos ou vertentes ditas como místicas. O sufismo, dentro da tradição religiosa do islã, pode ser definido como a busca de uma experiência direta com Deus (Allah).

${ }^{25}$ A noção de self pode ser definida como o senso experiencial de "ser e agir no mundo", de acordo com as capacidades e disposições de cada um (PINTO, 2002, p. 5).
} 
de abordagens intelectualistas. A linguagem para Csordas funcionaria como um veículo que permitiria a expressão intersubjetiva das experiências individuais, supondo que os princípios culturais inscritos no uso da linguagem seriam apenas indicadores simbólicos dos processos corporais que constituem a própria experiência. Entretanto Pinto (2002) discorda desse último ponto justamente por considerar que seu modelo acaba por separar a linguagem da dimensão da experiência. A fim de minimizar essa dicotomia, o autor propõe analisar o próprio vocabulário que descreve a experiência como sua parte constitutiva.

Concordo que o vocabulário da experiência desenvolve e delimita os conjuntos intelectuais, sensoriais e emocionais mobilizados pelos sujeitos, ao mesmo tempo em que eles proveem os instrumentos para transformar essas experiências em formas públicas. A comunicação e a descrição das experiências permitem comparações e questionamentos com base nas experiências de outras pessoas ou sobre os princípios normativos dos sistemas religiosos. Além disso, essas experiências criam um quadro de memórias coletivas e individuais que serve de modelo para futuras experiências, conforme sugere Pinto (2002). Os peregrinos de Sidi 'Ali apresentam marcações temporais assíduas para expressar a produção dessas experiências em termos de memória.

A interface entre os especialistas religiosos (fuqaha) e peregrinos encontra limitações para uma análise em profundidade das subjetividades, dado o caráter fluido desses últimos (BOISSEVAIN, 2006). Mesmo assim, insisto sobre as formas devocionais manifestadas no mausoléu de Sidi 'Ali ben Hamdouche como maneira de indicar o caráter intersubjetivo na produção das experiências de cura e/ou de proteção com base em normas religiosas, como no caso do islã. O processo terapêutico vigente apresenta elementos restauradores de ordem na vida social dos indivíduos (o que produz a noção de eficácia), mas também estabelece relações de vínculos entre os peregrinos com as forças de cura e/ou de proteção com o santo local a partir da mediação de agentes específicos (fuqaha) legitimados por suas formas tradicionais. 


\section{DINÂMICA NO MAUSOLÉU DE SIDI ‘ALI BEN HAMDOUCHE}

Situada na face sul da montanha de Zerhoun, a vila de Sidi 'Ali (comuna rural de Mesrhasiyne) faz parte de um conjunto de vilas rurais (Sidi Ahmed Dghoughi e Sidi Moussa ben 'Ali, por exemplo) e de cidades históricas (as ruínas romanas de Volubilis), que percorrem uma extensão territorial de relevo acidentado e desembocam no Médio Atlas. As estradas que cortam esse tipo de relevo acabam ligando esses pontos com as cidades mais próximas: Meknes e Fez. Ambos os centros urbanos adquirem papel relevante tanto no abastecimento dessas vilas, no que se refere à aquisição de produtos industrializados, quanto à comunicação com o mundo exterior. A vila de Sidi 'Ali está localizada a $26 \mathrm{~km}$ de Meknes (a capital imperial do país durante o século XVI, no governo de Moulay Ismail) e a $12 \mathrm{~km}$ de Moulay Idriss (local da fundação da dinastia dos Idríssidas $^{26}$ e da primeira capital do Marrocos).

A vida social ${ }^{27}$ da vila de Sidi 'Ali é organizada em quatro eixos: a) o comércio; b) o mausoléu de Sidi 'Ali ben Hamdouche; c) a fonte de água para a purificação corporal dos peregrinos ('Ayn Kabir); e d) a gruta de Aisha Qandisha (jinn). A vila sobrevive das atividades de comércio de roupas (djellaba) e calçados (babouche) provenientes da produção industrial de Fez. A maioria de seus consumidores é formada por mulheres que circulam entre suas lojas. Além disso, existe um comércio local que inclui cafés, restaurantes, mercearias, barbearia e uma farmácia presente em uma das três ruas existentes.

A área do mausoléu de Sidi 'Ali ben Hamdouche forma um complexo que abriga o túmulo do santo fundador da tariqa Hamdouchiya ${ }^{28}$ e que empres-

\footnotetext{
${ }^{26}$ Dinastia que reinou entre os anos de 789 e 985.

27 A vila também tem como atividade econômica principal a produção de azeitonas e as festas ligadas à produção de milho na região (Meknes), realizada no início da primavera. Sidi 'Ali faz parte de um circuito de peregrinação existente na região de Fez-Meknes, localizado entre as montanhas de Zerhoun. Os peregrinos organizam suas visitações aos santuários da vila conforme seus interesses e disponibilidades. As visitações se concentram geralmente nos finais de semana, quando os peregrinos dispõem de mais tempo para organizar suas práticas rituais e derivam, sobretudo, das possibilidades financeiras para patrocinar essas experiências.

28 Diversas crenças e práticas sufis presentes nas tariqas marroquinas, como as da Hamdouchiya, já foram denominadas como "heterodoxas" na metade do século XIX e no início do XX. Entretanto evito classificar as tariqas marroquinas com o rótulo de "populares" ou de "elites". Essas denominações não se justificam
} 
ta o nome à vila rural. Dois prédios compõem os espaços que organizam as peregrinações ao mausoléu. A parte principal, onde se localiza o túmulo do santo, encontrava-se interditada aos visitantes devido a obras para a restauração das estruturas internas. A área adjacente ao mausoléu inclui um minarete, de onde são emitidas as chamadas para as cinco orações ao longo do dia (adhan) por meio de alto-falantes instalados no alto da estrutura, e uma sala de orações (mussala) que também era utilizada para receber as doações dos peregrinos na forma de velas, água de rosa, incensos ou pães. Além disso, há o túmulo de Sidi Hafian (discípulo de Sidi 'Ali) e de outros descendentes do santo.

O mausoléu do santo patrono da tariqa (Sidi 'Ali ben Hamdouche) se encontra atualmente sem um líder oficial (naqib) desde 1982. O título de naqib no Marrocos se refere aos indivíduos que participam da mesma narrativa de linhagem ou de descendência direta ${ }^{29}$ da família do Profeta (shurfa) e que são reconhecidos ${ }^{30}$ como os representantes de uma tariqa perante o governo. Após essa data, o sucessor do naqib (seu filho) não conseguiu organizar, a partir de seu carisma, uma unidade política diante das quatro famílias que controlam o mausoléu. Ainda assim, ele conduziu suas atividades como naqib nessa comunidade sufi até sua morte, em 2004, quando coube ao seu filho mais velho - neto do naqib que falecera em 1982 - a busca de seu reconhecimento como legítimo sucessor da comunidade sufi. O problema dessa sucessão traz consigo não somente a capacidade de influenciar e desenvolver projetos em parceria com os demais discípulos da tariqa espalhados nos 32 locais de culto da Hamdouchiya no país, mas inclusive fora dele (Argélia e Tunísia). Nesse sentido, a imbricação entre poder religioso e político, tão conhecido do

para analisar o caráter das atividades e experiências rituais sufis, devido ao aspecto etnocêntrico contido nessas associações, o que acabou reforçando a divisão entre as práticas ligadas a uma ortodoxia islâmica vigente em oposição às práticas consideradas como as manifestações de heterodoxias. No final das contas, a produção desses discursos visa definir o que seria entendido como uma "tradição" (ASAD, 1986).

${ }^{29}$ No Marrocos, diversas famílias formam uma elite (econômica, política e intelectual) e uma comunidade privilegiada à parte da sociedade. Mais do que isso, a composição dessas famílias indica uma multiplicidade de posições sociais assumidas que vão desde suas ligações com a casa real, grupos étnicos envolvidos e a cooptação de personalidades locais (notáveis urbanos/rurais).

30 De 1961 a 1979, o uso do título de naqib no Marrocos estava legalmente ausente do edifício institucional do país. Mesmo que alguns indivíduos da shurfa portassem o título, eles não o exerciam legalmente, já que os decretos reais (dahirs sharif), responsáveis por sua legitimação, não foram renovados por Hassan II, entronizado em 1961. 
contexto marroquino (EICKELMAN, 1985), situa não só a relação de longa data de elites locais - como no caso da shurfa de Sidi 'Ali - com os santuários do país, mas também justifica a ausência temporária de investimentos locais para a melhoria da infraestrutura desse sítio devocional da vila.

Desde que iniciei meu trabalho etnográfico em 2012 na vila de Sidi 'Ali, durante o Mawlid al-Nabawi (celebração do aniversário do Profeta), parte do mausoléu estava fechado para obras de reparo das estruturas internas. Segundo os membros da tariqa Hamdouchiya, o risco de desabamento por causa do mau estado de conservação, especialmente das áreas que levam à tumba do santo, colocaria a vida das pessoas em risco. Na época, eu visitei internamente o mausoléu com alguns descendentes do santo e observei a necessidade dessas restaurações, visto a quantidade de estacas de madeira e de andaimes metálicos que fixavam parte dos tetos.

Essas contenções foram realizadas por engenheiros contratados pelo MHAI que, desde o ano de 2010, segundo os membros da tariqa Hamdouchiya, haviam se proposto a firmar um acordo de restauração do local. O acordo faz parte da nova política do governo de Mohammed VI, no poder desde 1999, em apoiar os patrimônios históricos ${ }^{31}$ do país. Apesar do discurso de preservação desse santuário, fundado no século XVIII, por parte de alguns descendentes do santo local ${ }^{32}$, não registrei em meu retorno ao local, em janeiro de 2015, qualquer mudança na estrutura física do mausoléu. Mesmo assim essa situação não inviabilizava a ida de peregrinos ao local na busca por experiências religiosas junto à tumba de Sidi 'Ali.

Diante da impossibilidade de patrocinar a reforma completa do mausoléu, a tariqa Hamdouchiya optou por transformar a antiga sala

\footnotetext{
${ }^{31}$ A produção e divulgação de eventos e festivais de música sufi, como os realizados pela tariqa Hamdouchiya em Sidi 'Ali, fazem parte da política governamental de promoção de imagem e discurso público de tolerância diante do avanço do salafismo (MUEDINI, 2015).

32 Entre os anos de 2014 e 2015, dois descendentes de Sidi 'Ali ben Hamdouche se destacaram dos demais e assumiram o protagonismo do mausoléu. O novo comando local provocou algumas mudanças quando estes indivíduos conseguiram estreitar os laços com o MHAI de Rabat por meio de suas redes pessoalizadas. A reforma completa do mausoléu foi estipulada, segundo as autoridades públicas, para dezembro de 2015. Nesse sentido, o acordo entre as partes (descendentes locais e MHAI) renova a presença das instituições governamentais no controle do campo político-religioso do país, uma vez que a tariqa Hamdouchiya se encontra em pleno processo de reestruturação das atividades religiosas.
} 
de orações (mussala) em uma nova zawiya ${ }^{33}$ para receber os peregrinos (BARTEL, 2016a). As duas portas do mausoléu, que funcionavam como local de entrada para a tumba de Sidi 'Ali, desde então passaram a servir de altar, onde eram depositadas as oferendas (pacote de velas com seis unidades, incensos, garrafas de água de rosa de $25 \mathrm{ml}$, pães, pacotes com um quilo de açúcar e tecidos de diversas cores) e feitas as doações de dinheiro em pratos de palha sob a responsabilidade dos fuqaha. Esses especialistas religiosos eram reconhecidos pela maioria dos peregrinos por serem os descendentes legítimos de Sidi 'Ali ben Hamdouche.

O comportamento dos peregrinos, especialmente das mulheres, merece atenção pelas formas devocionais para com o santo local. A crença no recebimento da baraka de Sidi 'Ali ben Hamdouche se realiza por meio das seguintes ações dos peregrinos, que se encontram sempre supervisionados pelos olhares atentos dos fuqaha: 1) estender a mão direita aberta rente à porta do mausoléu ao mesmo tempo em que se realiza uma prece individual; 2) tocar com a mão direita aberta a porta do mausoléu enquanto se recita uma prece individual; 3) beijar a mão (fechada ou aberta) que se usou para tocar a porta do mausoléu e levar ambas as mãos sobre o rosto; 4) bater na porta do mausoléu com a mão direita aberta três vezes ao mesmo tempo em que se realiza uma prece individual; 5) colocar a testa rente à porta do mausoléu, de pé, enquanto se realiza uma prece individual; 6) ficar sentado rente à porta do mausoléu ao mesmo tempo em que se recita uma prece individual; 7) colocar um incenso (jawi) na porta do mausoléu; 8) lançar e/ou libar água de rosa (zhar ma' ward) na porta do mausoléu e/ou em seus cantos; e 9) acender uma ou mais velas (sham'at) na escada e/ou na porta do mausoléu. Nesse sentido, a oferta de velas, incensos e garrafas de água de rosa nos portões do mausoléu, além da entrega de doações monetárias ${ }^{34}$ (moedas e notas), formam as materialidades encontradas pelos peregrinos junto aos fuqaha para negociar os serviços de cura e/ou de proteção desses especialistas religiosos.

\footnotetext{
33 Local ritual ou centro das atividades religiosas sufis.

34 Moedas nos valores de 1, 2, 5 ou 10 dirhams (MAD). Notas nos valores de 20 ou 50 dirhams (MAD). Em 2012, um real (BRL) equivalia, aproximadamente, a 4,5 dirhams (MAD).
} 
Os peregrinos podem utilizar os espaços públicos do mausoléu durante os horários de visitação, que está aberto das nove da manhã às seis da tarde. Dois fuqaha eram disponibilizados pela tariqa Hamdouchiya para atender às demandas dos peregrinos. Mohammed ${ }^{35}$ (62 anos) e Hassan (44 anos) desenvolvem dois estilos performáticos distintos no trato com os visitantes a partir da circulação e distribuição de baraka proveniente de Sidi 'Ali.

\section{OS ESPECIALISTAS E AS PRÁTICAS TERAPÊUTICAS}

Mohammed sempre usava um galabia ${ }^{36}$ branca e alternava sua atuação ora na nova zawiya, ora nas escadas (principalmente durante o verão) que levavam os peregrinos aos antigos portões principais do mausoléu. Na nova zawiya, ele constantemente praticava a leitura do Alcorão, o que não ocorria quando ele estava sentado nas escadas à espera dos visitantes. Vez ou outra, ele exibia vídeos do YouTube sobre homens, mulheres ou crianças recitando o Alcorão.

A trajetória de Mohammed como fqih no mausoléu de Sidi 'Ali decorre da sua aptidão em memorizar o Alcorão desde a adolescência. Ele era reconhecido na vila por proferir uma grande quantidade de capítulos corânicos (surat) com maestria técnica e domínio estético, do ponto de vista da maioria dos interlocutores. O "ofício de fqih", segundo ele, transcorreu diante dos inúmeros convites recebidos para recitar o Alcorão em eventos da tariqa Hamdouchiya (abertura de rituais sufis no mausoléu e de música popular na praça da vila) ou na casa de amigos. Após se aposentar, Mohammed julgou que era melhor aproveitar a habilidade com as evocações corânicas junto aos peregrinos como meio de complementar sua renda.

Já Hassan permanecia sempre nas escadas dos antigos portões principais do mausoléu de Sidi 'Ali. Diferente de Mohammed, ele dispunha de um tecido (shad) verde sobre um prato de palha ( $t^{\prime} b a g$ ) em um dos degraus da escada. Sobre o tecido havia elementos vegetais (cedro em pó) e minerais

\footnotetext{
35 Modifiquei os nomes dos interlocutores para preservar suas identidades.

${ }^{36}$ Peça de vestuário larga e comprida, que pode ter mangas largas ou curtas.
} 
(incenso branco - jawi byad) que formavam a base de sua "mistura especial" de cura e/ou proteção, segundo ele. Além disso, disponibilizava um braseiro de cerâmica contendo carvão ao lado do prato de palha, formando assim a parte instrumental desse fqih.

Hassan nunca teve a trajetória marcada por estudos formais para se tornar um fqih. Porém a maioria das preces mobilizadas eram reconhecidas entre os descendentes como vinculadas ao "tempo dos bravos homens" ${ }^{37}$ da tariqa Hamdouchiya. Sua inserção no cenário religioso local data da juventude e teve como marco a organização de um pequeno comércio de artigos religiosos (velas, água de rosa, incensos e pães) na frente das escadas do mausoléu de Sidi 'Ali. Os conhecimentos baseados na utilização de elementos vegetais e minerais, segundo ele, eram tributários do contato com os comerciantes da vila. Neste sentido, a escolha das preces e dos objetos a serem manipulados por ele era parte de um repertório tradicional e experimental desenvolvido por Hassan para lidar com as exigências dos peregrinos.

Segundo os dois fuqaha, os demais descendentes de Sidi 'Ali nunca se opuseram às suas atividades prestadas no mausoléu. Mesmo que houvesse alguma desconfiança por parte de alguns quanto à eficácia das ações realizadas por eles, todos concordavam com a necessidade de ter alguém para zelar pelos peregrinos. A maioria dos interlocutores se dizia assoberbado com as ocupações profissionais (comércio e produção rural) para dedicar algum tempo, por assim dizer, ao controle dos espaços internos e públicos do mausoléu. A associação ( rabita) dos descendentes de Sidi 'Ali, criada em 2006, estabeleceu como uma de suas metas a contratação de um fqih vindo de fora e formado por uma instituição governamental (MHAI) de Meknes, mas isso nunca se concretizou devido à falta de recursos financeiros.

Apresento a seguir três descrições sobre os modos de ação e as condutas religiosas atuantes que pude acompanhar entre os dois fuqaha da tariqa Hamdouchiya. Não espero extrair um quadro amplo de comparações definitivas

\footnotetext{
37 O uso dessa expressão entre os descendentes do santo patrono da Hamdouchiya era acionado pela memória afetiva dos sujeitos de que, no passado, ou seja, durante o período que correspondia à maioria das socializações dos interlocutores ao sufismo nos anos 1970, a tariqa possuía membros portadores de virtudes e valores religiosos que enalteciam a "tradição" comum, porém vivida localmente.
} 
entre os dois, em vez disso procuro identificar alguns princípios operantes nas formas de interação com os peregrinos. E, ainda, demonstrar que a realização da experiência terapêutica visando a cura e/ou proteção por parte do peregrino pode ser analisada concomitantemente aos discursos produzidos, sobretudo, pelas mulheres.

Certa vez, três mulheres chegaram às pressas ao mausoléu de Sidi 'Ali e perguntaram pela presença do fqih. Quando Mohammed se apresentou como o responsável pelo local, uma senhora exigiu uma prece para a amiga dela (Rachida, 31 anos, desempregada, residente de Casablanca), que se encontrava muito doente. Rachida, que reclamava de fortes dores por todo o corpo, caminhou amparada pelas amigas em direção a Mohammed. Quando ela finalmente atingiu os últimos degraus das escadas do mausoléu, subitamente desmaiou em cima do fqih. Mohammed posicionou Rachida ao seu lado, sentada na escada, fixando sua mão esquerda nas costas da paciente. O corpo de Rachida tremia e, por vezes, se contorcia em direção ao fqih, que procurava uma posição a fim de iniciar suas ações religiosas.

Quando finalmente of fih estabeleceu uma posição corporal fixa para a paciente, Mohammed colocou um tecido branco sobre a cabeça de Rachida e começou a recitar o Alcorão. Ele iniciou suas evocações corânicas com a abertura inicial (Surat al-Fatiha) e as finalizou alternando com alguns trechos (ayas) posteriores (Surat al-Baqarah). Mohammed tornou público para as demais mulheres presentes de que ele havia identificado a ação de um jinn sobre o corpo de Rachida, manifestado a partir das formas corporais apresentadas pela peregrina.

Mais tarde, Mohammed comentou comigo que as explicações iniciais dadas às mulheres tinham o intuito de despertar nelas os cuidados necessários sobre a figura de $\operatorname{shaytan}^{38}$, por intermédio das recitações do Alcorão feitas por ele. Mohammed se manteve, durante o período das evocações corânicas, com a mão direita sobre a cabeça de Rachida. Depois de um tempo, enquanto o corpo

\footnotetext{
${ }_{38}$ O termo shaytan representa também a figura mitológica de Iblis, o rei dos jnun. Em ambas as representações, a ideia do "mal" deve ser combatida pelos muçulmanos. Caso contrário, seu contato pode apresentar sérias consequências para a vida dos humanos.
} 
da peregrina permanecia trêmulo, Mohammed se aproximou de seu ouvido e pôs-se a recitar o Alcorão nessa posição. O corpo de Rachida alternava entre estados de tremores e de inércia durante os conteúdos expressos pelo fqih.

Quando Mohammed julgou que o jinn abandonou o corpo de Rachida, graças ao uso das palavras extraídas do Alcorão, muitas pessoas que estavam próximas do local se aproximaram das escadas do mausoléu para presenciar a performance de Mohammed. Após ter ficado uns vinte minutos sob a supervisão do fqih, Rachida esboçou uma reação de alívio diante das ações realizadas por Mohammed. Quando o fqih terminou seu ciclo de evocações corânicas, ele tirou o tecido branco ${ }^{39}$ que cobria a cabeça da peregrina e finalizou a sessão de cura e/ou de proteção despejando sobre a cabeça de Rachida água de rosas ${ }^{40}$ proveniente das garrafas de $25 \mathrm{ml}$ vendidas nas lojas de artigos religiosos de Sidi 'Ali.

"Você está bem agora", disse o fqih. A peregrina se levantou lentamente e ficou de pé por um tempo, escorada por suas amigas, ouvindo as últimas instruções de Mohammed. Ele fez questão de reforçar a importância da leitura do Alcorão diante de possíveis novos ataques de jnun sobre a peregrina e, também, para as demais mulheres. Elas não responderam absolutamente nada ao fqih e se puseram a caminhar rumo ao hotel em que estavam hospedadas.

No dia seguinte, eu conversei com Rachida no hotel Marhaba ${ }^{41}$. Ela dizia se sentir melhor depois da intervenção do fqih da tariqa Hamdouchiya sobre seu corpo. Contou-me ainda que era a terceira vez que visitava Sidi 'Ali pelos mesmos motivos. "Preciso aprender mais sobre o Alcorão. É verdade que sua leitura nos protege, mas não sei o que acontece comigo. Não tenho paciência para lê-lo", comentou frustrada. Ela descreveu a experiência nas escadas do mausoléu em termos de lembrança e de esquecimento com relação às ações do fqih.

\footnotetext{
${ }_{39}$ Mohammed disse usar o tecido branco como forma de acalmar os pacientes, por considerar que o recurso controla as ansiedades dos indivíduos, e as palavras evocadas do Alcorão para combater as forças maléficas dos jnun.

${ }^{40}$ Mohammed disse usar a água de rosas para provocar um "estado de despertar" nos indivíduos rumo a "uma nova jornada" (o que reforça a valorização da prática da peregrinação).

${ }^{41}$ Frequentei esse local sempre que me hospedava na vila para a realização do meu trabalho de campo (BARTEL, 2016b).
} 
Recordou-se de ter ouvido algumas frases do Alcorão enquanto sentia seu corpo tremer, mas não se lembrava do uso do tecido branco sobre sua cabeça.

Rachida reconheceu o poder das palavras do Alcorão para o restabelecimento de sua condição física. A crença de que algum jinn era o responsável por sua situação foi aceita pela peregrina, o que reforçava a ideia da eficácia contida nas evocações corânicas para o afastamento desses seres sobre os indivíduos. Além disso, ela indicou os usos do tecido branco e da água de rosas por parte de Mohammed como ações de purificação corporal. A peregrina elogiou os saberes de Mohammed e sua conduta na resolução da situação. "O fqih é descendente de um santo. Sidi 'Ali tem um grande valor. Assim, seus descendentes têm meu respeito", concluiu emocionada. As recitações provenientes do Alcorão, o uso de determinados objetos (tecido branco e água de rosas) sobre o corpo da peregrina e a autoridade investida na figura do faih como descendente legítimo do santo local e portador de baraka garantiram o efeito terapêutico sobre Rachida.

Em outra situação, um grupo de quatro mulheres chegou para entregar alguns objetos ao mausoléu de Sidi 'Ali. A oferta consistia em dois pacotes de velas, quatro garrafas de água de rosas e uma quantia de 50 dirhams em dinheiro. Uma das peregrinas (Samira, 42 anos, dona de casa, residente de Meknes) requisitou os serviços de Hassan alegando ter dores intensas nas costas, fato que a impedia de andar direito.

O fqih se levantou das escadas, misturou parte do cedro em pó com o incenso branco sobre o tecido verde do prato de palha com a mão direita e lançou-o no braseiro. Enquanto a fumaça proveniente dessa queima de materiais (vegetal e mineral) não acendia, Hassan voltou a misturar o cedro em pó com o incenso branco na mão direita e, dessa vez com a mão fechada, exigiu que a mulher indicasse os locais onde sentia as dores. A peregrina se aproximou do fqih e apontou as regiões das costas com os "pontos de aflição", segundo ela.

Hassan pediu então para que a peregrina se aproximasse do braseiro e que fechasse os olhos. Quando Samira atendeu os pedidos, o fqih deu três giros com a mão direita fechada, contendo a mistura, sobre a cabeça dela. 
Depois disso, ele passou a mão direita rente ao ombro esquerdo, ao estômago e, por último, aos dois tornozelos da peregrina, quando realizou uma prece ${ }^{42}$.

Após a recitação de Hassan, Samira permaneceu com os olhos fechados e também murmurou uma prece individual. Quando o fqih terminou de passar a mistura rente às partes do corpo de Samira, ele lançou todo o material de sua mão direita sobre o braseiro. Imediatamente após o estalo provocado pelo lançamento do material, uma fumaça branca começou a subir. Hassan pediu para que Samira se posicionasse o mais próximo possível do braseiro para receber a fumaça. Após alguns instantes dessa purificação corporal ${ }^{43}$, o fqih levantou as duas mãos para o alto e recitou outros trechos (ayas) corânicos (Surat al-Baqarah). As mulheres que acompanhavam a peregrina levantaram as mãos rentes aos seus rostos e responderam "amin" (amém), após o final de cada sentença pronunciada pelo fqih.

Em seguida, Hassan quebrou uma garrafa de água de rosas na escada que leva aos portões do mausoléu, fato que provocou uma reação de espanto por parte das mulheres. "Nunca vi ninguém fazer isso", disse uma das peregrinas ao fqih. "Foi para marcar a presença de vocês no mausoléu", respondeu ele. Depois de descer as escadas, Hassan pegou uma vela branca dos pacotes ofertados por Samira e a jogou sobre o tecido verde que continha o cedro em pó e os incensos brancos. Deixou que parte da mistura grudasse na vela e a entregou para Samira dizendo que aquela vela era sua e que ela deveria acendê-la na próxima semana, mais especificamente na sexta-feira - dia sagrado para os muçulmanos. Em posse do "souvenir religioso", nos termos do próprio fqih, Samira deu mais 50 dirhams para Hassan em troca de preces para todas as mulheres do grupo e, também, por outras velas que pudessem ter a mistura vegetal-mineral.

\footnotetext{
42 Árabe (darija): Ah sidi salli 'ala nbi. Salli 'ala nbi. Lah y j'el l-mahabba hia lokhra. Lahy bellegh l-maqsoud. Lah y bellegh l-gharad. Lah y j'ell-mahabba li lahu y khelsek lah. Amin, amin wa lhamdu lillah arabl'alamin. Tradução: Ah meu senhor, reze para o profeta. Reze para o profeta. Talvez Deus provenha o amor para a outra vida. Talvez Deus realize a intenção. Talvez Deus realize o objetivo. Talvez Deus provenha o amor para ele e ele irá pagar você. Amém, amém e que Deus figure nos dois mundos.

${ }^{43}$ Certa vez questionei Mohammed quanto à eficácia dessa prática oferecida por Hassan. Ele me disse que o uso de incenso está prescrito pelo profeta Mohammed como elemento capaz de tirar o "olho da inveja" (al-'ayn) das pessoas.
} 
Diante do pedido, o fqih não recuou e se pôs logo a recomeçar as atividades religiosas de cura e/ou de proteção novamente.

Muito tempo depois, outra peregrina do grupo (Imane, 45 anos, bibliotecária, residente de Meknes) retirou três fotos da carteira e pediu para que Hassan fizesse uma prece para seus filhos, mais especificamente para um que, segundo Imane, apresentava graves problemas de saúde. O fqih recolheu as três fotos com a mão direita e, com ela fechada, fez uma prece para todos os filhos da peregrina enquanto jogava um pouco de cedro em pó com incenso branco no braseiro com a mão esquerda. Quando a fumaça branca novamente subiu, Hassan aproximou sua mão que segurava as fotos em direção à fumaça.

$\mathrm{O}$ fqih entregou as fotos à peregrina e pediu para que ela revelasse os nomes de cada um de seus filhos. Após tomar ciência dos respectivos nomes, Hassan unificou uma prece para seus três filhos e, depois, quebrou uma garrafa de água de rosas na base da escada do mausoléu. Imane decidiu abrir outra garrafa de água de rosas e bebeu parte do líquido, deixando o restante em um dos degraus da escala. No final, antes das peregrinas partirem, o fqih quebrou mais uma garrafa de água de rosas, dessa vez no canto da escada. Isso foi algo muito comemorado pelas mulheres, que realizaram a performance de tzaghri$t a^{44}$ em frente do mausoléu.

Tanto Samira quanto Imane me disseram dias depois que ambas estavam circulando há bastante tempo por diversas cidades marroquinas (Moulay Idriss ${ }^{45}$, Sidi Kacem ${ }^{46}$ e Moussaoua ${ }^{47}$ ) com o intuito de conseguir algum tipo de cura e/ou proteção para os problemas pelos quais estavam passando. A escolha dessas três cidades não expressava um sistema de peregrinação existente no país, mas decorria de escolhas individuais baseadas nas especificidades dos santos

\footnotetext{
${ }^{44}$ A fórmula verbal "Bênção e paz sobre o Mensageiro de Deus. O lado do profeta, Deus está do lado honesto" (Sla w slam 'la rasoul Allah. Ila jah ila jah sidna Mohammed, Allah m'a jah l'ali) é utilizada junto com uma série de prolongamentos sonoros estridentes conhecidos como tzaghrita. O termo diz respeito à execução de sons provenientes de intensas movimentações das línguas das mulheres no interior de suas bocas.

${ }_{45}$ Primeira cidade Imperial do Marrocos localizada a $30 \mathrm{~km}$ de Meknes, que tem como referência a tumba de Moulay Idriss.

${ }^{46}$ Cidade localizada a $51 \mathrm{~km}$ de Meknes, que tem como referência a tumba de Sidi Kacem - século XVII.

47 Cidade localizada a $235 \mathrm{~km}$ de Meknes, que tem como referência a tumba de Sidi Moussa Ben 'Ali século XVI.
} 
citados. As duas disseram que jamais haviam visitado a vila de Sidi 'Ali, mas, como reconheciam o valor de sua bênção divina (baraka), resolveram arriscar uma visita. Questionadas por mim se voltariam à Sidi 'Ali como forma de agradecimento pelas possíveis bênçãos obtidas por intermédio do santo local, as peregrinas não souberam responder.

"Sempre que arranjamos um tempo, visitamos diversos mausoléus até nos sentirmos bem", disse Samira contendo o choro. As formas de atuação realizadas por Hassan agradaram as duas peregrinas, principalmente no tocante ao uso da mistura como elemento purificador de seus corpos e à quebra de garrafas de água de rosa como forma de marcar sua presença ${ }^{48}$ junto ao santo. Além disso, as preces individuais do fqih em parceria com algumas passagens do Alcorão criavam, segundo Imane, um ambiente de proteção e de alguma previsibilidade quanto ao fim das aflições.

\section{CONSIDERAÇÕES FINAIS}

Os diferentes níveis de mobilização realizados pelos especialistas religiosos (fuqaha), no mausoléu de Sidi 'Ali ben Hamdouche, estabeleciam uma comunicação com os peregrinos que expressavam as mais variadas formas de reconhecimento de eficácia e de devoção. Cabe destacar as falas emotivas de todas as interlocutoras envolvidas (Rachida, Samira e Imane) como forma de se atentar para os significados existentes (principalmente os de purificação) durante as visitas dessas mulheres. As formas encontradas por essas peregrinas junto aos fuqaha apresentavam tanto as dimensões tradicionais instituídas no imaginário religioso, como as recitações do Alcorão e as preces de evocação ao santo local, quanto a de situações performáticas, como os distintos usos das velas, dos incensos e das garrafas de água de rosas.

Os fuqaha, por outro lado, utilizavam-se da legitimidade atribuídas pelos peregrinos sobre eles como forma de propagar e difundir as capacidades de

\footnotetext{
${ }^{48}$ A ideia de presença se refere à forma pública assumida na lógica de peregrinação ao mausoléu por meio das performances desenvolvidas por Hassan.
} 
cura e/ou proteção advindas de Sidi 'Ali. Os objetos ofertados pelos visitantes (velas, incensos, garrafas de água de rosas, pães, açúcar, tecidos e dinheiro) marcavam o início das interações com a figura religiosa local visando a supressão dos infortúnios vividos. A experiência individual por parte dos peregrinos, resultante da ida ao mausoléu, era acompanhada por um período de espera específico, que determinaria se os efeitos de cura e/ou de proteção foram eficazes. Caso se confirmasse, novos desejos e motivações poderiam resultar na organização de outras idas ao mausoléu.

Se toda prece é um discurso ritual adaptado a uma sociedade religiosa (MAUSS, 2005), os usos das palavras, nas preces individuais e nas recitações de trechos do Alcorão pelos fuqaha, adquirem relevância tanto para os especialistas religiosos quanto para os peregrinos. Diferente da importância dada às palavras durante a ação ritual, que expressava apenas os comportamentos estereotipados formados por sequências de atos não verbais e/ou pela manipulação dos objetos, a enunciação e seus pronunciamentos constituem a própria experiência (TAMBIAH, 1968). Além disso, a eficácia não apenas reside porque assim determinou e declarou a religião, mas também porque atende aos anseios de um conjunto de subjetividades inseridas em diversas tradições religiosas.

O papel da materialidade dos objetos religiosos utilizados (velas, incensos e garrafas de água de rosas) confluía para a eficácia entre os peregrinos. Mesmo que Mohammed e Hassan apresentassem ênfases completamente distintas quanto às suas performances religiosas, o uso das palavras impetrava uma dimensão purificadora às experiências de cura e/ou de proteção aos visitantes, seja em conformidade com a prática que utiliza o tecido branco do primeiro fqih, seja com a mistura (vegetal-mineral) que produz a fumaça branca do segundo. Por último, as ações que envolviam os usos das garrafas de água rosas (libações e destruições), provisoriamente marcavam o fim das ações rituais dos especialistas religiosos com os peregrinos. Mesmo assim, os métodos de Mohammed e Hassan diferem de uma ideia de tradição religiosa em voga, tendo em vista os usos atribuídos ao texto-recitação (Mohammed) ou aos outros mediadores materiais (Hassan) utilizados nos peregrinos. 
O culto aos santos no Marrocos permite que se critiquem os limites teórico-metodológicos impostos entre o que se convencionou denominar de "ortodoxia" e "islã popular". Esses termos, tomados a partir de uma concepção de modernidade sobre a religião islâmica (GELLNER, 1981), dificultam os entendimentos, por exemplo, das novas possibilidades de se obter uma "cura legítima" (al-ruqya al-shar 'iyya) dentro da sociedade marroquina contemporânea (SPADOLA, 2014). Essa ideia de legitimidade no processo terapêutico permite repensar as disputas em termos de uma ortodoxia disponível e mobilizada para fins específicos ou, muitas vezes, almejada como "correta", vinculada às práticas cotidianas dos sujeitos. Sobre esse ponto, a tensão entre tradição discursiva/discurso autorizado (ASAD, 1986) e cotidiano religioso (SCHIELKE; DEBEVEC, 2012) perpassam os interlocutores, uma vez que o problema da autoridade e da relação entre ética e ação simbólica continua a ser um ponto mesurado no Marrocos. Nesse sentido, repensar as agências dos especialistas e as subjetividades dos sujeitos envolvidos possibilita problematizar as performances e as eficácias mobilizadas na produção de rituais de cura.

As experiências terapêuticas de Rachida, Samira e Imane, a partir do contato com a baraka de Sidi 'Ali, foram produzidas em parceria com os especialistas, que seguem distintas tradições, mas que, mesmo assim, conseguem uma inserção com os peregrinos no caráter purificador contido em suas práticas. Desse modo, reitero as seguintes caraterísticas quanto aos princípios operacionais atuantes na interface dos fuqaha com as experiências de cura e/ou de proteção no mausoléu de Sidi 'Ali: a importância das preces, das recitações do Alcorão e dos objetos (velas, incensos e garrafas de água de rosa) como parte dos dispositivos intelectuais, sensoriais e emocionais que garantem a experiência terapêutica por parte dos peregrinos. Além disso, o contexto marroquino permite que os polos entre o que se denomina como ortodoxia islâmica (recitações corânicas) versus a atuação de práticas populares (o culto de santos e a circulação de objetos religiosos) possam ocorrer sem maiores constrangimentos a partir dos valores existentes nas formas devocionais praticadas, principalmente, por mulheres. 
Dito de outra maneira, o tema da ortodoxia englobaria a questão dos sentidos produzidos pelos sujeitos por meio dos objetos existentes na peregrinação (materialidade) e das concepções femininas (gênero) de como lidar com o culto aos santos. Contudo esse debate remete a boa parte da produção dos anos 1970 e 1980, que marcariam o ponto alto dos estudos antropológicos sobre o islã e uma discussão mais particular, especificamente no Marrocos, suportada pelas pesquisas envolvendo a dimensão de gênero sobre a religiosidade islâmica (LAGHZAOUI, 1992; MERNISSI, 1981). É nesse sentido que a proposta analítica de um campo de subjetividades existentes contribui para superar a inoperância dessas distinções "clássicas" já observadas no contexto marroquino. Para isso, a combinação do papel das agências entre especialistas religiosos (fuqaha) e peregrinas situadas nesses santuários, como o mausoléu de Sidi 'Ali, propiciam novos arranjos nas práticas de cura do Marrocos contemporâneo.

\section{REFERÊNCIAS BIBLIOGRÁFICAS}

1. AMSTER, Ellen; EL AOUED, Rajae. Medicine and the saints: science, Islam, and the colonial encounter in Morocco, 1877-1956. Austin: University of Texas Press, 2013.

2. AOUATTAH, Ali. Interprétations et traitements traditionnels de la maladie mentale au Maroc: pour une psychiatrie culturelle marocaine. Casablanca: Okad, 2008.

3. APPADURAI, Arjun. Introdução: mercadorias e a política de valor. In: APPADURAI, Arjun (org.). A vida social das coisas: as mercadorias sob uma perspectiva cultural. Niterói: UFF, 2008. p. 15-88.

4. ASAD, Talal. The idea of an anthropology of Islam. Washington, DC: Georgetown University, 1986.

5. BANDAK, Andreas; BOYLSTON, Tom. The "orthodoxy" of orthodoxy on moral imperfection, correctness, and deferral in religious worlds. Religion and Society: Advances in Research, New York, n. 5, p. 25-46, 2014.

6. BARTEL, Bruno Ferraz. A dinâmica da baraka no mausoléu de Sidi 'Ali ben Hamdouche, Marrocos. Revista Equatorial, Natal, v. 3, n. 4, p. 11-37, 2016 a.

7. BARTEL, Bruno Ferraz. Representação, peregrinação, sacrifício e possessão no culto a Aisha Qandisha. Rio de Janeiro: Autografia, 2016b. 
8. BOISSEVAIN, Katia. Sainte parmi les saints: Sayyda Mannûbiya ou les recompositions cultuelles dans la Tunisie contemporaine. Paris: Maisonneuve et Larose, 2006.

9. CORNELL, Vincent. Realm of the saint: power and authority in Moroccan Sufism. Austin: University of Texas Press, 1998.

10. CRAPANZANO, Vincent. The Hamadsha: a study in Moroccan ethnopsychiatry. Berkeley: University of California Press, 1973.

11. CSORDAS, Thomas. The sacred self: a cultural phenomenology of charismatic healing. Berkeley: University of California Press, 1994.

12. DERMENGHEM, Émille. Le culte des saints dans l'islam maghrébin. Paris: Gallimard, 1954.

13. DWYER, Daisy. Women, Sufism, and decision-making in Moroccan Islam. In: BECK, Lois; KEDDIE, Nikki (ed.). Women in the Muslim World. Cambridge, MA: Harvard University Press, 1978. p. 585-598.

14. EICKELMAN, Dale. Moroccan Islam: tradition and society in a pilgrimage center. Austin: University of Texas Press, 1976. (Modern Middle East Series 1).

15. 15. EL HAITAMI, Meriem. Women in Morocco: re-conceptualizing religious activism. American Journal of Islamic Social Sciences, Herndon, v. 30, n. 4, p. 128-141, 2013.

16. EICKELMAN, Dale. Knowledge and power in Morocco: the education of a twentieth century notable. Princeton: Princeton University Press, 1985.

17. GELLNER, Ernest. A pendulum swing theory of Islam. Annales Marocaines de Sociologie, Paris, v. 1, p. 5-14, 1968.

18. GELLNER, Ernest. Muslim society. Cambridge, UK: Cambridge University Press, 1981.

19. GOOD, Byron. Medicine, rationality, and experience: an anthropological perspective. Cambridge, MA: Harvard University Press, 1994.

20. LAGHZAOUI, Latifa. Women and shrines in urban Morocco: the case of the PatronSaint of Sale. London: University of London, 1992.

21. MAUSS, Marcel. A prece. In: MAUSS, Marcel. Ensaios de sociologia. São Paulo: Perspectiva, 2005. p. 229-324.

22. MERNISSI, Fatima. Les femmes et les saints. Lamalif, Casablanca, v. 128, p. 40-44, 1981.

23. MUEDINI, Fait. Sponsoring Sufism: how governments promote "mystical Islam" in their domestic and foreign policies. New York: Palgrave Macmillan, 2015. 
24. NAAMOUNI, Khadija. Le culte de Bouya Omar. Casablanca: Editions EDDIF, 1993.

25. PINTO, Paulo Gabriel Hilu da Rocha. Mystical bodies: ritual, experience and the embodiment of Sufism in Syria. 2002. Dissertation (PhD in Philosophy) Boston University, Boston, 2002.

26. RAUSCH, Margaret. Bodies, boundaries and spirit possession: Moroccan women and the revision of tradition. Bielefeld: Transcript, 2000.

27. RHANI, Zakaria. Saints et rois: la genèse du politique au Maroc. Anthropologica, Toronto, v. 50, n. 2, p. 375-388, 2008.

28. SCHIELKE, Samuli. Ambivalent commitments: troubles of morality, religiosity and aspiration among young Egyptians. Journal of Religion in Africa, Gainesville, v. 39, n. 2, p. 158-185, 2009.

29. 29. SCHIELKE, Samuli; DEBEVEC, Liza. Introduction. In: DEBEVEC, Liza (ed.). Ordinary lives and grand schemes: an anthropology of everyday religion. New York: Berghahn Books, 2012. p. 1-16.

30. SPADOLA, Emilio. The calls of Islam: Sufis, Islamists, and mass mediation in urban Morocco. Bloomington: Indiana University Press, 2014.

31. TAMBIAH, Stanley. The magical power of words. Man, Hoboken, v. 3, n. 2, p. 175-208, 1968.

32. WESTERMARCK, Edward. Ritual and belief in Morocco. New York: University Books, 1968.

33. WHEELER, Brannon. Mecca and Eden: ritual, relics, and territory in Islam. Chicago: University of Chicago Press, 2006. 